\title{
Effect of Nocturnal Hypoxia on Nocturia in Patients With Obstructive Sleep Apnea
}

\author{
Jae Hoon Chung ${ }^{1, \star}$, Hong Sang Moon ${ }^{1}$, Sung Yul Park ${ }^{1}$, Kyung Rae Kim², Seok Hyun Cho ${ }^{2}$, Yong Tae Kim \\ ${ }^{1}$ Department of Urology, Hanyang University College of Medicine, Seoul, Korea \\ ${ }^{2}$ Department of Otorhinolaryngology-Head and Neck Surgery, Hanyang University College of Medicine, Seoul, Korea
}

\begin{abstract}
Purpose: To identify the association between nocturia and obstructive sleep apnea (OSA), we compared results of polysomnography (PSG) with the presence or absence of nocturia in patients with suspected OSA.

Methods: Patients underwent PSG for suspected OSA. The International Prostate Symptom Score and quality of life (IPSS/ QoL) questionnaire was evaluated to assess voiding symptoms that may affect sleep quality. The results of PSG were compared between patient groups with or without nocturia.

Results: In logistic regression analysis, age (odds ratio [OR], 1.052; $\mathrm{P}=0.004)$, diabetes mellitus $(\mathrm{OR}, 6.675 ; \mathrm{P}<0.001)$, mean $\mathrm{O}_{2}$ saturation $(\mathrm{OR}, 0.650 ; \mathrm{P}=0.017)$, oxygen desaturation index (ODI) $3(\mathrm{OR}, 1.193 ; \mathrm{P}=0.010)$, and $\mathrm{ODI} 4(\mathrm{OR}, 1.136$; $\mathrm{P}=0.014$ ) affected nocturia independently among the OSA-suspected patients.

Conclusions: Hypoxia caused by OSA affects the incidence of nocturia. Less desaturated OSA patients with nocturia may require more urological evaluation and treatment for nocturia even after the correction of OSA.
\end{abstract}

Keywords: Nocturia; Apnea; Sleep; Hypoxia

- Research Ethics: This study was approved by the Institutional Review Board of Hanyang University Hospital (approval number: 2017-05-004001). Each patient provided written informed consent of participation.

- Grant/Fund Support: This work was supported by the Bio \& Medical Technology Development Program of the National Research Foundation (NRF) \& funded by the Korean government (MIST) (No. 2017M3A9E2064631).

- Conflict of Interest: HSM, an associate editor of the Editorial Board of International Neurourology Journal, is the second author of this article. However, he played no role whatsoever in the editorial evaluation of this article or the decision to publish it. No potential conflict of interest relevant to this article was reported.

\section{INTRODUCTION}

Nocturia refers to the need to urinate more than once during sleep [1]. Nocturia is more prevalent in women than in men, and the incidence of nocturia increases with age [2]. Nocturia is highly prevalent, and affects up to $60 \%$ of elderly people over 70 years of age [3]. Nocturia not only increases the risk of falls or fractures, but also interferes with normal sleep and degrades
Corresponding author: Seok Hyun Cho (D) https://orcid.org/0000-0001-8218-5894 Department of Otorhinolaryngology-Head and Neck Surgery, Hanyang University College of Medicine, 222-1 Wangshimni-ro, Seongdong-gu, Seoul 04763, Korea E-mail: shcho@hanyang.ac.kr / Tel: +82-2-2290-8583 / Fax: +82-2-2293-3335

Co-corresponding author: Yong Tae Kim (iD https://orcid.org/0000-0002-7646-2098 Department of Urology, Hanyang University College of Medicine, 222-1 Wangshimni-ro, Seongdong-gu, Seoul 04763, Korea

E-mail: ytkimuro@hanyang.ac.kr / Tel: +82-2-2290-8594 / Fax: +82-2-2290-8593

${ }^{*}$ Current affiliation: Department of Urology, Samsung Medical Center, Seoul, Korea. Submitted: January 21, 2019 / Accepted after revision: April 4, 2019 (c) (1) $\$$ This is an Open Access article distributed under the terms of the Creative Commons Attribution Non-Commercial License (http://creativecommons.org/licenses/by-nc/4.0/) which permits unrestricted non-commercial use, distribution, and reproduction in any medium, provided the original work is properly cited. 
quality of life $[4,5]$.

The cause of nocturia can be divided into 3 main categories: reduced nocturnal bladder capacity, 24-hour polyuria, and nocturnal polyuria. These three causes can act independently or in combination to induce nocturia [6]. In particular, obstructive sleep apnea (OSA) is a major cause of nocturnal polyuria [7]. The prevalence of OSA is $2 \%-10 \%$ of the population, and OSA is considered an incapacitating chronic disease in which sleep apnea is repeated due to pharyngeal collapse during sleep [8,9]. OSA is considered a common cause of sleep disorders [10].

The association of nocturia with OSA has been reported in a number of studies. Endeshaw et al. [11] reported in a community-based study that sleep-disordered breathing increased nocturia episodes by nearly 100\%. Oztura et al. [12] reported that, as the severity of OSA increases, the incidence of nocturia increases. The use of continuous positive airway pressure (CPAP) as a treatment for OSA or the surgical correction of OSA can improve nocturia $[13,14]$.

The association between nocturia and OSA has not been clarified. Therefore, to evaluate the association factors between OSA and nocturia, we compared the results of polysomnography (PSG) according to presence or absence of nocturia in patients with suspected OSA among Korean.

\section{MATERIALS AND METHODS}

\section{Patients}

This prospective study was conducted from January 2013 to November 2017 at Hanyang University Hospital. A total of 345 patients with sleep apnea who underwent PSG for suspected OSA were enrolled in the study. Exclusion criteria included patients under 19 years of age, patients currently undergoing urology treatment with nocturia, and patients with urinary tract infection. Included patients underwent physical examination, routine laboratory blood test, and urinalysis. In addition, they completed the Epworth Sleepiness Scale (ESS) and Pittsburgh Sleep Quality Index (PSQI) questionnaires. The International Prostate Symptom Score and Quality of Life (IPSS/QoL) questionnaire was evaluated to assess voiding symptoms that could affect sleep quality. In the IPSS/QoL questionnaire, nocturia was considered present if the patient recorded $>2$ on the item 7 question "How many times did you typically get up at night to urinate?” Baseline characteristics, results of PSG, and questionnaire results were compared between patients with nocturia (nocturia group) and patients without nocturia (control group).

\section{Polysomnography}

In-lab overnight PSG (Allis 5; Respironics, Murrysville, PA, USA) was performed to diagnose the presence of OSA, as described previously [15]. Briefly, respiratory events were diagnosed as apnea or hypopnea, and the apnea-hypopnea index (AHI) was calculated as the total number of events per hour of sleep. All sleep recordings were scored by a trained sleep technologist according to the recent criteria of the second American Academy of Sleep Medicine manual [16].

\section{Statistical Analysis}

In this study, Student $\mathrm{t}$-test was used for continuous variables and chi-square test for categorical variables. The analysis of PSG values according to presence or absence of nocturia was performed through analysis of covariance and logistic regression analysis. Moreover, paired t-test and chi-square test was performed in propensity score matching analysis based on age, hypertension and diabetes mellitus (DM). IBM SPSS ver. 18.0 (IBM Co., Armonk, NY, USA) was used as a statistical analysis program, and P-values $<0.05$ were considered statistically significant.

\section{Ethics Statement}

The study was performed in agreement with applicable laws and regulations, good clinical practices, and ethical principles as described in the Declaration of Helsinki. This study was approved by the Institutional Review Board of Hanyang University Hospital (approval number: 2017-05-004-001). Each patient provided written informed consent of participation.

\section{RESULTS}

\section{Patient Characteristics}

Of the 345 patients examined, 304 patients were included in this study. Of these, 83 had nocturia (nocturia group) and 221 showed no nocturia (control group). The mean ages of the nocturia group and control group were $55.46 \pm 10.97$ years and $45.19 \pm 12.56$ years, respectively $(\mathrm{P}<0.001)$. There was no significant difference in sex ratio between the 2 groups $(\mathrm{P}=0.067)$. The prevalence of hypertension and DM was greater in the nocturia group than the control group (hypertension: $57.83 \%$ vs. $28.96 \%$, respectively, $\mathrm{P}<0.001$; DM: $33.73 \%$ vs. $7.24 \%$, respectively, $\mathrm{P}<0.001)$. The waist-hip ratio (WHR) was $0.95 \pm 0.06$ in the nocturia group and $0.93 \pm 0.57$ in the control group $(\mathrm{P}=0.015)$, although there was no significant difference between the 2 groups in body mass index and neck circumference. The nocturia group scored higher on the IPSS/QoL ques- 
Table 1. Baseline characteristics of patients included in the study $(\mathrm{n}=304)$

\begin{tabular}{|c|c|c|c|}
\hline Characteristic & Nocturia $(n=83)$ & Control $(n=221)$ & $\mathrm{P}$-value ${ }^{\mathrm{a})}$ \\
\hline Age (yr) & $55.46 \pm 10.97$ & $45.19 \pm 12.56$ & $<0.001$ \\
\hline Male sex & $54(65.06)$ & $167(75.57)$ & $0.067^{\mathrm{b})}$ \\
\hline Hypertension & $48(57.83)$ & $64(28.96)$ & $<0.001^{\mathrm{b})}$ \\
\hline Diabetes mellitus & $28(33.73)$ & $16(7.24)$ & $<0.001^{\mathrm{b})}$ \\
\hline Body mass index $\left(\mathrm{kg} / \mathrm{m}^{2}\right)$ & $26.81 \pm 4.89$ & $26.49 \pm 4.09$ & 0.603 \\
\hline Neck circumference (cm) & $38.69 \pm 4.30$ & $38.72 \pm 3.53$ & 0.952 \\
\hline Waist circumference (cm) & $96.27 \pm 11.87$ & $94.78 \pm 10.76$ & 0.319 \\
\hline WHR & $0.95 \pm 0.06$ & $0.93 \pm 0.57$ & 0.015 \\
\hline IPSS & $7.32 \pm 0.80$ & $5.39 \pm 0.36$ & $<0.001$ \\
\hline QoL & $1.24 \pm 0.14$ & $1.23 \pm 0.08$ & $<0.001$ \\
\hline \multicolumn{4}{|l|}{ Polysomnography } \\
\hline Total sleep time (min) & $233.83 \pm 86.32$ & $275.08 \pm 83.78$ & $<0.001$ \\
\hline Sleep efficacy (\%) & $74.02 \pm 14.31$ & $80.99 \pm 11.55$ & $<0.001$ \\
\hline N3 (\%) & $0.50 \pm 1.75$ & $2.41 \pm 5.73$ & 0.003 \\
\hline REM (\%) & $14.69 \pm 7.21$ & $16.25 \pm 7.08$ & 0.094 \\
\hline Snoring time (\%) & $42.61 \pm 23.77$ & $48.38 \pm 23.23$ & 0.060 \\
\hline Apnea index (events/hr) & $22.76 \pm 28.45$ & $14.44 \pm 19.52$ & 0.004 \\
\hline Hypopnea index (events/hr) & $16.43 \pm 14.52$ & $16.07 \pm 14.45$ & 0.845 \\
\hline AHI (events/hr) & $39.19 \pm 32.58$ & $30.50 \pm 25.83$ & 0.016 \\
\hline Low $\mathrm{O}_{2}(\%)$ & $77.61 \pm 14.80$ & $81.50 \pm 9.87$ & 0.009 \\
\hline Mean $\mathrm{O}_{2}(\%)$ & $94.08 \pm 3.06$ & $95.40 \pm 1.95$ & $<0.001$ \\
\hline T90 & $10.38 \pm 16.87$ & $4.20 \pm 8.86$ & $<0.001$ \\
\hline ODI3 (events/hr) & $37.31 \pm 32.56$ & $28.66 \pm 24.98$ & 0.014 \\
\hline ODI4 (events/hr) & $31.18 \pm 32.18$ & $21.13 \pm 23.01$ & 0.003 \\
\hline Arousal index (events/hr) & $42.33 \pm 22.19$ & $35.40 \pm 19.63$ & 0.014 \\
\hline ESS & $9.05 \pm 6.36$ & $8.48 \pm 4.73$ & 0.398 \\
\hline PSQI & $9.48 \pm 4.10$ & $7.14 \pm 3.18$ & $<0.001$ \\
\hline
\end{tabular}

Values are presented as mean \pm standard deviation.

WHR, waist-hip ratio; IPSS, International Prostate Symptom Score; QoL, quality of life; REM, rapid eye movement; AHI, apnea-hypopnea index; T90, time spent in desaturation below $90 \%$; ODI3, oxygen desaturation index $\geq 3 \%$; ODI4, oxygen desaturation index $\geq 4 \%$; ESS, Epworth Sleepiness Scale; PSQI, Pittsburgh Sleep Quality Index.

${ }^{\text {a) }}$ Student t-test. ${ }^{\text {b) }}$ Chi-square test.

tionnaire than the control group $(7.32 \pm 0.80 / 1.24 \pm 0.14$ points vs. $5.39 \pm 0.36 / 1.23 \pm 0.08$ points, respectively, $\mathrm{P}<0.001)$ (Table 1$)$.

\section{Polysomnography}

The total sleep time of the nocturia group was $233.83 \pm 86.32$ minutes, which was shorter than that of the control group (275.08 \pm 83.78 minutes $)(\mathrm{P}<0.001)$, and sleep efficacy was lower in the nocturia group $(74.02 \% \pm 14.31 \%)$ than in the controls $(80.99 \% \pm 11.55 \%, \mathrm{P}<0.001)$. Stage N3 sleep was $0.50 \% \pm 1.75 \%$ in the nocturia group and $2.41 \% \pm 5.73 \%$ in the control group $(\mathrm{P}=0.003)$. The apnea index $(\mathrm{AI})$ and $\mathrm{AHI}$ were higher in the nocturia group than in the control group (AI: nocturia group, $22.76 \pm 28.45$ events/hr; control group, $14.44 \pm 19.52$ events/hr; $\mathrm{P}=0.004$ ) (AHI: nocturia group, $39.19 \pm 32.58$ events/hr; control group, $30.50 \pm 25.83$ events $/ \mathrm{hr} ; \mathrm{P}=0.016$ ). The respiratory disturbance index was $42.52 \pm 31.00$ for the nocturia group and $34.76 \pm 25.06$ for the control group $(\mathrm{P}=0.025)$. Low $\mathrm{O}_{2}$ saturation levels during sleep were $77.61 \% \pm 14.80 \%$ in the nocturia 
Table 2. Clinical and sleep-related factors for nocturia in obstructive sleep apnea

\begin{tabular}{|c|c|c|c|}
\hline Variable & Nocturia $(n=83)$ & Control $(n=221)$ & P-value ${ }^{a}$ \\
\hline Total sleep time (min) & $233.83 \pm 86.32$ & $275.08 \pm 83.78$ & 0.026 \\
\hline Sleep efficacy (\%) & $74.02 \pm 14.31$ & $80.99 \pm 11.55$ & 0.001 \\
\hline N3 (\%) & $0.50 \pm 1.75$ & $2.41 \pm 5.73$ & 0.374 \\
\hline REM (\%) & $14.69 \pm 7.21$ & $16.25 \pm 7.08$ & 0.059 \\
\hline Snoring time (\%) & $42.61 \pm 23.77$ & $48.38 \pm 23.23$ & 0.069 \\
\hline Apnea index (events/hr) & $22.76 \pm 28.45$ & $14.44 \pm 19.52$ & 0.051 \\
\hline Hypopnea index (events/hr) & $16.43 \pm 14.52$ & $16.07 \pm 14.45$ & 0.560 \\
\hline AHI (events/hr) & $39.19 \pm 32.58$ & $30.50 \pm 25.83$ & 0.195 \\
\hline Respiratory effort-related arousal & $3.57 \pm 4.04$ & $4.26 \pm 3.35$ & 0.166 \\
\hline Respiratory disturbance index & $42.52 \pm 31.00$ & $34.76 \pm 25.06$ & 0.273 \\
\hline Low $\mathrm{O}_{2}(\%)$ & $77.61 \pm 14.80$ & $81.50 \pm 9.87$ & 0.205 \\
\hline Mean $\mathrm{O}_{2}(\%)$ & $94.08 \pm 3.06$ & $95.40 \pm 1.95$ & 0.004 \\
\hline T90 & $10.38 \pm 16.87$ & $4.21 \pm 8.86$ & 0.005 \\
\hline ODI3 (events/hr) & $37.31 \pm 32.56$ & $28.66 \pm 24.98$ & 0.194 \\
\hline ODI4 (events/hr) & $31.18 \pm 32.18$ & $21.13 \pm 23.01$ & 0.049 \\
\hline Arousal index (events/hr) & $42.33 \pm 22.19$ & $35.40 \pm 19.63$ & 0.080 \\
\hline ESS & $9.05 \pm 6.36$ & $8.48 \pm 4.73$ & 0.196 \\
\hline PSQI & $9.48 \pm 4.10$ & $7.14 \pm 3.18$ & $<0.001$ \\
\hline
\end{tabular}

Values are presented as mean \pm standard deviation.

REM, rapid eye movement; AHI, apnea-hypopnea index; T90, time spent in desaturation below 90\%; ODI3, oxygen desaturation index $\geq 3 \%$; ODI4, oxygen desaturation index $\geq 4 \%$; ESS, Epworth Sleepiness Scale; PSQI, Pittsburgh Sleep Quality Index.

Analysis of covariance.

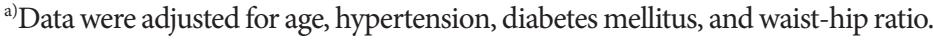

group and $81.50 \% \pm 9.87 \%$ in the control group $(\mathrm{P}=0.009)$. Mean $\mathrm{O}_{2}$ saturation values were $94.08 \% \pm 3.06 \%$ for the nocturia group and $95.40 \% \pm 1.95 \%$ for the control group $(\mathrm{P}<0.001)$. Time spent in desaturation below $90 \%$ (T90), oxygen desaturation index $\geq 3 \%$ (ODI3), and oxygen desaturation index $\geq 4 \%$ (ODI4) were significantly higher in the nocturia group. The degree of arousal was $42.33 \pm 22.19$ in the nocturia group and $35.40 \pm 19.63$ in the control group $(\mathrm{P}=0.014)$. ESS questionnaire results were not significantly different between the 2 groups, but PSQI questionnaire results were higher in the nocturia group $(9.48 \pm 4.10)$ than in the control group $(7.14 \pm 3.18)(\mathrm{P}<0.001)$ (Table 1$)$.

The results of PSG, when adjusted by age, hypertension, DM, and WHR, showed a significant difference in total sleep time, sleep efficacy, mean $\mathrm{O}_{2}$ saturation, T90, ODI4, and PSQI between the nocturia group and the control group (Table 2). Logistic regression analysis confirmed that age (odds ratio [OR], 1.052; $\mathrm{P}=0.004)$, $\mathrm{DM}(\mathrm{OR}, 6.675 ; \mathrm{P}<0.001)$, mean $\mathrm{O}_{2}$ saturation ( $\mathrm{OR}, 0.650 ; \mathrm{P}=0.017)$, ODI3 (OR, 1.193; $\mathrm{P}=0.010)$, ODI4
(OR, 1.136; $\mathrm{P}=0.014)$, and PSQI questionnaire score (OR, 1.264; $\mathrm{P}<0.001$ ) affected nocturia independently (Table 3 ).

In propensity score matching analysis based on age, hypertension, and DM showed that IPSS ( $12.05 \pm 7.47$ vs. $6.32 \pm 5.42$, $\mathrm{P}<0.001)$, QoL $(3.56 \pm 1.26$ vs. $2.33 \pm 1.14, \mathrm{P}<0.001)$ and PSQI $(9.73 \pm 4.36$ vs. $6.14 \pm 3.09, \mathrm{P}<0.001)$ was significantly different between nocturia group and control group, respectively. Moreover, mean $\mathrm{O}_{2}$ saturation value in nocturia group was $94.18 \pm 3.08$ and control group was $95.15 \pm 2.13(\mathrm{P}=0.033)$ (Table 4).

\section{DISCUSSION}

In present study, PSG results of patients with nocturia among OSA patients showed that total sleep time, sleep efficacy, mean $\mathrm{O}_{2}$ saturation, T90, and ODI4 were worse than that in OSA patients without nocturia. Moreover, our results indicate that mean $\mathrm{O}_{2}$ saturation, ODI3, ODI4, and the result of the PSQI questionnaire were independent factors for nocturia. 
Table 3. Logistic regression analysis for nocturia in obstructive sleep apnea

\begin{tabular}{|c|c|c|c|c|c|c|c|c|}
\hline \multirow{2}{*}{ Variable } & \multicolumn{4}{|c|}{ Univariate analysis regression } & \multicolumn{4}{|c|}{ Multivariate analysis regression } \\
\hline & $\beta$ & S.E. $\beta$ & OR $(95 \% \mathrm{CI})$ & P-value & $\beta$ & S.E. $\beta$ & OR $(95 \% \mathrm{CI})$ & P-value \\
\hline \multicolumn{9}{|l|}{ Clinical } \\
\hline Age & 0.073 & 0.013 & $1.076(1.049-1.103)$ & $<0.001$ & 0.050 & 0.017 & $1.052(1.016-1.088)$ & 0.004 \\
\hline Male sex & 0.507 & 0.278 & $1.661(0.962-2.866)$ & 0.068 & 0.271 & 0.429 & $1.311(0.565-3.042)$ & 0.528 \\
\hline HTN & 1.213 & 0.267 & $3.364(1.993-5.680)$ & $<0.001$ & 0.335 & 0.374 & $1.398(0.671-2.911)$ & 0.371 \\
\hline $\mathrm{DM}$ & 1.875 & 0.348 & $6.523(3.296-12.908)$ & $<0.001$ & 1.898 & 0.478 & $6.675(2.618-17.022)$ & $<0.001$ \\
\hline BMI & 0.017 & 0.028 & $1.017(0.960-1.077)$ & 0.571 & & & & \\
\hline Neck circumference & -0.002 & 0.034 & $0.998(0.933-1.067)$ & 0.948 & & & & \\
\hline Waist circumference & 0.012 & 0.011 & $1.012(0.990-1.035)$ & 0.296 & & & & \\
\hline WHR & 5.728 & 2.276 & $307.416(3.548-26,635.680)$ & 0.012 & -2.441 & 3.545 & $0.087(0.000-90.617)$ & 0.491 \\
\hline \multicolumn{9}{|l|}{ Questionnaire } \\
\hline ESS & 0.021 & 0.024 & $1.021(0.973-1.071)$ & 0.397 & & & & \\
\hline PSQI & 0.182 & 0.038 & $1.200(1.114-1.292)$ & $<0.001$ & 0.234 & 0.051 & $1.264(1.144-1.397)$ & $<0.001$ \\
\hline \multicolumn{9}{|l|}{ Polysomnography } \\
\hline TST & -0.006 & 0.002 & $0.995(0.992-0.997)$ & $<0.001$ & -0.004 & 0.002 & $0.996(0.991-1.001)$ & 0.081 \\
\hline $\mathrm{SE}$ & -0.041 & 0.010 & $0.960(0.941-0.979)$ & $<0.001$ & -0.031 & 0.017 & $0.969(0.938-1.001)$ & 0.059 \\
\hline $\mathrm{N} 3$ & -0.197 & 0.074 & $0.821(0.710-0.949)$ & 0.008 & -0.100 & 0.079 & $0.905(0.775-1.056)$ & 0.206 \\
\hline REM & -0.032 & 0.019 & $0.968(0.933-1.005)$ & 0.091 & & & & \\
\hline Snoring & -0.011 & 0.006 & $0.990(0.979-1.000)$ & 0.057 & 0.001 & 0.008 & $1.001(0.986-1.017)$ & 0.910 \\
\hline $\mathrm{AI}$ & 0.015 & 0.005 & $1.015(1.004-1.026)$ & 0.005 & -0.006 & 0.017 & $0.994(0.960-1.028)$ & 0.716 \\
\hline $\mathrm{HI}$ & 0.002 & 0.009 & $1.002(0.985-1.019)$ & 0.844 & & & & \\
\hline AHI & 0.011 & 0.004 & $1.011(1.002-1.020)$ & 0.017 & 0.029 & 0.07 & $1.030(0.898-1.180)$ & 0.675 \\
\hline Low $\mathrm{O}_{2}$ & -0.027 & 0.011 & $0.973(0.953-0.994)$ & 0.011 & 0.047 & 0.028 & $1.048(0.992-1.107)$ & 0.094 \\
\hline Mean $\mathrm{O}_{2}$ & -0.223 & 0.057 & $0.800(0.716-0.894)$ & $<0.001$ & -0.430 & 0.18 & $0.650(0.457-0.926)$ & 0.017 \\
\hline T90 & 0.039 & 0.011 & $1.040(1.018-1.062)$ & $<0.001$ & -0.017 & 0.037 & $0.983(0.914-1.057)$ & 0.645 \\
\hline ODI3 & 0.011 & 0.005 & $1.011(1.002-1.020)$ & 0.016 & 0.177 & 0.068 & $1.193(1.044-1.364)$ & 0.010 \\
\hline ODI4 & 0.014 & 0.005 & $1.014(1.005-1.023)$ & 0.004 & 0.128 & 0.052 & $1.136(1.026-1.258)$ & 0.014 \\
\hline Arousal index & 0.016 & 0.006 & $1.016(1.004-1.028)$ & 0.01 & 0.005 & 0.019 & $1.005(0.970-1.043)$ & 0.770 \\
\hline
\end{tabular}

S.E., standard error; OR, odds ratio; CI, confidence interval; HTN, hypertension; DM, diabetes mellitus; BMI, body mass index; WHR, waist-hip ratio; ESS, Epworth Sleepiness Scale; PSQI, Pittsburgh Sleep Quality Index; TST, total sleep time; SE, sleep efficacy; REM, rapid eye movement; AI, apnea index; HI, hypopnea index; AHI, apnea-hypopnea index; T90, time spent in desaturation below 90\%; ODI3, oxygen desaturation index $\geq 3 \%$; ODI4, oxygen desaturation index $\geq 4 \%$.

According to the International Continence Society, nocturia is defined as waking up to urinate at least once during sleep [6]. However, the number of times that urination is required to define a subject as having nocturia is controversial. According to a population study, at least 2 urination events constitute meaningful nocturia affecting well-being and perceived health. And they concluded that one urination per night does not identify subjects with interference from nocturia and is not a suitable criterion for clinically relevant nocturia [17]. Therefore, nocturia could be defined as 2 or more urination events during sleep $[1,17]$. In present study, nocturia was defined as 2 or more events of requiring urination during sleep in order to compare PSG characteristics prominently between the nocturia group and control group of OSA-suspected patients.

In a population-based survey of 19,165 adults, the overall prevalence of nocturia ( $\geq 1 \mathrm{void} /$ night) in respondents 18 years of age 
Table 4. Comparison of characteristics and polysomnography after propensity score matching based on age, hypertension, and diabetes mellitus

\begin{tabular}{|c|c|c|c|}
\hline Variable & Nocturia $(n=66)$ & Control $(n=66)$ & P-value ${ }^{a)}$ \\
\hline Age (yr) & $53.39 \pm 10.90$ & $52.85 \pm 10.37$ & 0.630 \\
\hline Male sex & $51(77.27)$ & $42(63.64)$ & $0.086^{\mathrm{b})}$ \\
\hline Hypertension & $33(50.00)$ & $34(51.51)$ & $0.862^{\mathrm{b})}$ \\
\hline Diabetes mellitus & $13(19.70)$ & $12(18.18)$ & $0.824^{\mathrm{b})}$ \\
\hline Body mass index $\left(\mathrm{kg} / \mathrm{m}^{2}\right)$ & $26.59 \pm 4.24$ & $26.11 \pm 3.35$ & 0.469 \\
\hline Neck circumference (cm) & $38.48 \pm 4.25$ & $38.97 \pm 3.37$ & 0.463 \\
\hline Waist circumference $(\mathrm{cm})$ & $95.70 \pm 10.78$ & $94.45 \pm 9.53$ & 0.482 \\
\hline WHR & $0.95 \pm 0.59$ & $0.95 \pm 0.54$ & 0.548 \\
\hline IPSS & $12.05 \pm 7.47$ & $6.32 \pm 5.42$ & $<0.001$ \\
\hline QoL & $3.56 \pm 1.26$ & $2.33 \pm 1.14$ & $<0.001$ \\
\hline \multicolumn{4}{|l|}{ Polysomnography } \\
\hline Total sleep time (min) & $237.37 \pm 87.33$ & $250.60 \pm 87.42$ & 0.396 \\
\hline Sleep efficacy (\%) & $74.35 \pm 14.43$ & $77.39 \pm 12.76$ & 0.177 \\
\hline N3 (\%) & $0.51 \pm 1.75$ & $1.38 \pm 4.11$ & 0.115 \\
\hline REM (\%) & $15.23 \pm 7.42$ & $15.49 \pm 5.73$ & 0.840 \\
\hline Snoring time (\%) & $40.91 \pm 23.64$ & $45.59 \pm 21.79$ & 0.224 \\
\hline Apnea index (events/hr) & $20.58 \pm 25.92$ & $18.44 \pm 22.58$ & 0.743 \\
\hline Hypopnea index (events/hr) & $16.29 \pm 15.31$ & $17.16 \pm 15.04$ & 0.698 \\
\hline AHI (events/hr) & $36.87 \pm 30.95$ & $35.56 \pm 26.02$ & 0.797 \\
\hline Low $\mathrm{O}_{2}(\%)$ & $78.45 \pm 14.56$ & $79.53 \pm 11.20$ & 0.624 \\
\hline Mean $\mathrm{O}_{2}(\%)$ & $94.18 \pm 3.08$ & $95.15 \pm 2.13$ & 0.033 \\
\hline T90 & $9.34 \pm 3.08$ & $5.30 \pm 9.49$ & 0.076 \\
\hline ODI3 (events/hr) & $35.44 \pm 31.08$ & $33.63 \pm 25.60$ & 0.710 \\
\hline ODI4 (events/hr) & $29.44 \pm 30.11$ & $25.48 \pm 24.71$ & 0.401 \\
\hline Arousal index (events/hr) & $41.42 \pm 21.27$ & $38.48 \pm 19.62$ & 0.432 \\
\hline ESS & $9.42 \pm 6.61$ & $8.15 \pm 4.66$ & 0.255 \\
\hline PSQI & $9.73 \pm 4.36$ & $6.14 \pm 3.09$ & $<0.001$ \\
\hline
\end{tabular}

Values are presented as mean \pm standard deviation.

WHR, waist-hip ratio; IPSS, International Prostate Symptom Score; QoL, quality of life; REM, rapid eye movement; AHI, apnea-hypopnea index; T90, time spent in desaturation below 90\%; ODI3, oxygen desaturation index $\geq 3 \%$; ODI4, oxygen desaturation index $\geq 4 \%$; ESS, Epworth Sleepiness Scale; PSQI, Pittsburgh Sleep Quality Index.

${ }^{\text {a) }}$ Student $\mathrm{t}$-test. ${ }^{\text {b) }}$ Chi-square test.

and older was $48.6 \%$ in men and $54.5 \%$ in women. When nocturia was defined as 2 voids/night, the prevalence decreased to $20.9 \%$ in men and $24.0 \%$ in women [2]. In present study showed a higher prevalence of nocturia ( $\geq 2$ void/night) $(27.30 \%$; male, $24.43 \%$; female, 34.94\%) than the previous study even though the high percentage of males $(72.70 \%)$ and low mean age $(48.00 \pm 12.96)$. These results may be due to our subjects being OSA patients.

Nocturia shows an increased incidence in elderly patients, and in patients with DM, hypertension, congestive heart failure, and urological diseases such as overactive bladder and benign prostate hyperplasia [18]. In particular, 59.6\% of DM patients have reported nocturia more than twice [19]. The results of present study also confirm that age and DM are associated independently with nocturia.

There are 2 proposed mechanisms by which OSA affects nocturia. First, negative thoracic pressure due to airway obstruction 
increases venous return to the heart, resulting in increased atrial natriuretic peptide (ANP) and increased urine volume [20]. Second, hypoxia caused by OSA increases the amount of ANP secretion by increasing pulmonary vasoconstriction and right atrial transmural pressure [21]. Our results are consistent with the second proposed mechanism. The mean $\mathrm{O}_{2}$ saturation was significantly lower and the T90 and ODI4 values were significantly higher in the nocturia group than in the control group. Logistic regression analysis revealed that mean $\mathrm{O}_{2}$ saturation, ODI3, and ODI4 values influenced nocturia independently. Moreover, in propensity score matched analysis, mean $\mathrm{O}_{2}$ saturation in nocturia group was significantly lower than control group. In present study, we screened pulmonary diseases such as chronic obstructive pulmonary disease and asthma, which may affect hypoxia. There was no enrolled respiratory disease patient except for one asthma patient in nonnocturia group.

Usually, the AHI is used to assess the diagnosis and severity of OSA. OSA is defined as $\geq 5 \mathrm{AHI}$ events per hour of sleep [22]. Most previous studies showing the association between OSA and nocturia evaluated OSA with AHI and assessed the association between AHI and nocturia [7,23]. However, in the present study, AHI did not appear to have a significant association with nocturia. On the other hand, the degree of desaturation showed a significant correlation with nocturia. ODI is an outcome of OSA and indicates the extent of oxygen desaturation. ODI3 (or 4) defined as the number of desaturations per hour of at least 3\% or $4 \%$ from baseline [24]. ODI also shows the severity of OSA [25]. Therefore, our results suggest that OSA does not induce nocturia, but hypoxia caused by OSA induces nocturia.

According Finamore et al. [26], they reported that nocturia is associated with intermittent desaturation (ODI3) rather than severity and length of hypoxia represented by T90. However, in this study, although there was no significant difference in logistic regression, a significant difference in T90 was found between the 2 groups with adjusted for age, hypertension, DM, and WHR. In the previous study, the PSG parameters such as AHI, ODI and T90 are lower than those of the present study, and it can be inferred that the severity of sleep apnea is lower than that of this study. As ODI increases, T90 is also increased. This may be the reason for the difference in T90 between the 2 groups.

In a meta-analysis of five randomized controlled trials, Wang et al. [27] reported that CPAP improves nocturia and QoL in patients with OSA. However, previous studies have not evaluated the cause or mechanism of improvement of nocturia after CPAP treatment. In addition, Park et al. [14] reported that nocturia im- proved after surgical correction for OSA, but $27.03 \%$ of patients reported no improvement in nocturia. However, no comparative analysis of the degree of hypoxia was performed in this study. In the present study, we confirmed that hypoxia caused by OSA affects nocturia, and suggests that if OSA is corrected, nocturia will improve. However, patients who have nocturia after OSA treatment may need additional urological evaluation.

The present study had some limitations. There was no urological evaluation such as a voiding diary, uroflowmetry, or a urodynamic study. And confirming the change pattern of nocturia after correcting OSA in these patients, we could have a clearer assessment of the association between OSA and nocturia. Lack of evaluation of this part is another limitation. However, a relatively large number of patients were enrolled, and independent factors affecting nocturia were identified among OSA patients. Therefore, our results suggest that patients who are not expected to improve their nocturia can be screened.

In conclusion, hypoxia caused by OSA is considered as affecting factor to nocturia. And patients who have nocturia after correction of the OSA may need urological examination.

\section{AUTHOR CONTRIBUTION STATEMENT}

- Full access to all the data in the study and takes responsibility for the integrity of the data and the accuracy of the data analysis: JHC

- Study concept and design: SHC

- Acquisition of data: $S H C$

- Analysis and interpretation of data: JHC, YTK

- Drafting of the manuscript: JHC

- Critical revision of the manuscript for important intellectual content: YTK, SYP, HSM

- Statistical analysis: JHC

- Obtained funding: $\mathrm{SHC}$

- Administrative, technical, or material support: KRK

- Study supervision: SHC, YTK

\section{REFERENCES}

1. Bosch JL, Weiss JP. The prevalence and causes of nocturia. J Urol 2010;184:440-6.

2. Irwin DE, Milsom I, Hunskaar S, Reilly K, Kopp Z, Herschorn S, et al. Population-based survey of urinary incontinence, overactive bladder, and other lower urinary tract symptoms in five countries: results of the EPIC study. Eur Urol 2006;50:1306-14. 
3. Yoshimura K, Terada N, Matsui Y, Terai A, Kinukawa N, Arai Y. Prevalence of and risk factors for nocturia: Analysis of a health screening program. Int J Urol 2004;11:282-7.

4. Middelkoop HA, Smilde-van den Doel DA, Neven AK, Kamphuisen HA, Springer CP. Subjective sleep characteristics of 1,485 males and females aged 50-93: effects of sex and age, and factors related to self-evaluated quality of sleep. J Gerontol A Biol Sci Med Sci 1996;51:M108-15.

5. Stewart RB, Moore MT, May FE, Marks RG, Hale WE. Nocturia: a risk factor for falls in the elderly. J Am Geriatr Soc 1992;40:121720.

6. van Kerrebroeck P, Abrams P, Chaikin D, Donovan J, Fonda D, Jackson S, et al. The standardisation of terminology in nocturia: report from the Standardisation Sub-committee of the International Continence Society. Neurourol Urodyn 2002;21:179-83.

7. Niimi A, Suzuki M, Yamaguchi Y, Ishii M, Fujimura T, Nakagawa T, et al. Sleep apnea and circadian extracellular fluid change as independent factors for nocturnal polyuria. J Urol 2016;196:1183-9.

8. Mannarino MR, Di Filippo F, Pirro M. Obstructive sleep apnea syndrome. Eur J Intern Med 2012;23:586-93.

9. Leger D, Bayon V, Laaban JP, Philip P. Impact of sleep apnea on economics. Sleep Med Rev 2012;16:455-62.

10. Subramanian S, Guntupalli B, Murugan T, Bopparaju S, Chanamolu S, Casturi L, et al. Gender and ethnic differences in prevalence of self-reported insomnia among patients with obstructive sleep apnea. Sleep Breath 2011;15:711-5.

11. Endeshaw YW, Johnson TM, Kutner MH, Ouslander JG, Bliwise DL. Sleep-disordered breathing and nocturia in older adults. J Am Geriatr Soc 2004;52:957-60.

12. Oztura I, Kaynak D, Kaynak HC. Nocturia in sleep-disordered breathing. Sleep Med 2006;7:362-7.

13. Miyazato M, Tohyama K, Touyama M, Nakamura H, Oshiro T, Ueda $\mathrm{S}$, et al. Effect of continuous positive airway pressure on nocturnal urine production in patients with obstructive sleep apnea syndrome. Neurourol Urodyn 2017;36:376-9.

14. Park HK, Paick SH, Kim HG, Park DH, Cho JH, Hong SC, et al. Nocturia improvement with surgical correction of sleep apnea. Int Neurourol J 2016;20:329-34.

15. Lim YH, Choi J, Kim KR, Shin J, Hwang KG, Ryu S, et al. Sex-specific characteristics of anthropometry in patients with obstructive sleep apnea: neck circumference and waist-hip ratio. Ann Otol Rhinol Laryngol 2014;123:517-23.

16. Berry RB, Budhiraja R, Gottlieb DJ, Gozal D, Iber C, Kapur VK, et al. Rules for scoring respiratory events in sleep: update of the 2007 AASM Manual for the Scoring of Sleep and Associated Events. De- liberations of the Sleep Apnea Definitions Task Force of the American Academy of Sleep Medicine. J Clin Sleep Med 2012;8:597-619.

17. Tikkinen KA, Johnson TM 2nd, Tammela TL, Sintonen H, Haukka J, Huhtala $\mathrm{H}$, et al. Nocturia frequency, bother, and quality of life: how often is too often? A population-based study in Finland. Eur Urol 2010;57:488-96.

18. Fitzgerald MP, Litman HJ, Link CL, McKinlay JB; BACH Survey Investigators. The association of nocturia with cardiac disease, diabetes, body mass index, age and diuretic use: results from the BACH survey. J Urol 2007;177:1385-9.

19. James R, Hijaz A. Lower urinary tract symptoms in women with diabetes mellitus: a current review. Curr Urol Rep 2014;15:440.

20. Hoshiyama F, Hirayama A, Tanaka M, Taniguchi M, Ohi M, Momose $\mathrm{H}$, et al. The impact of obstructive sleep apnea syndrome on nocturnal urine production in older men with nocturia. Urology 2014;84:892-6.

21. Witthaus MW, Nipa F, Yang JH, Li Y, Lerner LB, Azadzoi KM. Bladder oxidative stress in sleep apnea contributes to detrusor instability and nocturia. J Urol 2015;193:1692-9.

22. Young T, Palta M, Dempsey J, Skatrud J, Weber S, Badr S. The occurrence of sleep-disordered breathing among middle-aged adults. N Engl J Med 1993;328:1230-5.

23. Tuncer M, Yazici O, Kafkasli A, Sabuncu K, Salepci B, Narter F, et al. Critical evaluation of the overactive bladder and urgency urinary incontinence association with obstructive sleep apnea syndrome in a relatively young adult male population. Neurourol Urodyn 2017;36:1804-8.

24. Collop NA, Anderson WM, Boehlecke B, Claman D, Goldberg R, Gottlieb DJ, et al. Clinical guidelines for the use of unattended portable monitors in the diagnosis of obstructive sleep apnea in adult patients. Portable Monitoring Task Force of the American Academy of Sleep Medicine. J Clin Sleep Med 2007;3:737-47.

25. Fabius TM, Benistant JR, Bekkedam L, van der Palen J, de Jongh FHC, Eijsvogel MMM. Validation of the oxygen desaturation index in the diagnostic workup of obstructive sleep apnea. Sleep Breath 2019;23:57-63.

26. Finamore P, Scarlata S, Laudisio A, Galdi F, Pipita ME, Chiarella I, et al. Occurrence of nocturia is not mediated by nocturnal hypoxia length and severity in patients with sleep-disordered breathing. Sleep Med 2018;45:69-73.

27. Wang T, Huang W, Zong H, Zhang Y. The Efficacy of continuous positive airway pressure therapy on nocturia in patients with obstructive sleep apnea: a systematic review and meta-analysis. Int Neurourol J 2015;19:178-84. 